American Journal of Environmental Sciences 4 (6): 615-619, 2008

ISSN 1553-345X

(C) 2008 Science Publications

\title{
Public Perception of Local Communities towards the Sustainable Management of Laguna Lake, Philippines
}

\author{
Glenn L. Sia Su and Julio Cervantes \\ Department of Biology, De La Salle University, Taft, Manila, Philippines
}

\begin{abstract}
Common failures in resolving multiple use conflicts are attributed to the inability of institutions to recognize and incorporate people's perceptions towards the resource. This study aims to determine the local communities' perceptions and factors influencing their perceptions towards Laguna Lake and its sustainable management. Copies of a self-administered questionnaire were distributed to systematically selected householders situated near and far from the Laguna Lake, Philippines. Correlation analysis determined the factors influencing the householder's perception. Results showed that attitudes, income and willingness to manage the lake affect the local communities' perception ( $\mathrm{P}<$ 0.10). Results also showed that most respondents recognized that the lake is deteriorating due to pollution and each individual can take a role to sustainably manage it.
\end{abstract}

Key words: Environment, perception, water resource, management

\section{INTRODUCTION}

Laguna Lake is the country's biggest freshwater resource and one of the largest in the Southeast Asian region. $\mathbf{I}$ is endowed in natural resources providing numerous uses and benefits for multiple users. At present, Laguna Lake is continuously meeting the needs of numerous sectors of society particularly as a source of freshwater supply. Studies have stressed that conflicts arising from multiple users contribute to the diminishing of the resources and the deterioration of the environment worldwide ${ }^{[1,2]}$.

There is a widespread awareness on the continuous deterioration of the quality of Laguna Lake and this has created a crucial interest to protect and sustainably manage the resource not just for the benefits that we derived from it but on the benefits it provides us in maintaining the integrity of the ecological processes of the environment. The national and local governments have continuously introduced programs and legislative measures to protect the lake but the situation brought about by the conflicts of multiple uses of Laguna Lake has virtually created daunting challenges towards the success of the measures and in the protection of the lake's condition. Studsrod and Wegge ${ }^{[3]}$ have identified that the common failure in most legislative approaches have been brought about by the inability of institutions to recognize and incorporate the perspectives and insights of the users themselves like the local communities depending on the resource. The success of resolving the issues and concerns governing the environment depends on how well the local communities themselves view the environment and its complex processes and on how greatly they are involved in managing it.

The conflicts arising from multiple users have always been a principal management problem faced by most communities ${ }^{[4,5]}$. Studies have indicated that the evident causes resulting to these conflicts of multiple users starts from the actual use and attitudes of people particularly towards the environment ${ }^{[6]}$. People commonly engage in activities that threaten the environment because of the want of maximizing the immediate economic benefits withstanding the potential costs it may incur to the environment. This study aims to determine the local communities' perceptions towards the lake, towards their use of the lake, towards what they can do for the environment and what they suggest the government can do for the environment are essential so as to understand how each one of us can play or take an important role in attaining a sustainable environment. Wells, Barnett and Moriarty ${ }^{[7]}$ presents that people's perceptions towards their environment are essential however are shaped by several influences. This study provides benchmark information on the perceptions of the local community particularly the users depending on the lake. The study also aims to assess the possible influences that may affect the local communities' perception towards their environment particularly towards the Laguna Lake. The findings

Corresponding Author: Glenn L. Sia Su, 12 D Cleveland Tower, Asiaworld City, E. Aguinaldo Blvd., Parañaque City, Philippines Tel: +632-8793014 Fax: +632-5360228 
from this study may be useful to decision makers particularly in developing policies and programs that will help meet and be responsive to the changing times and changing needs of the users.

\section{MATERIALS AND METHODS}

Five provinces, 12 cities and 49 municipalities bound Laguna Lake. A community in Muntinlupa city was selected to represent an onsite community $(0-500 \mathrm{~m})$ to the Laguna Lake and another community in Parañaque was selected to represent the offsite community (501-1000 meters away from Laguna Lake). A total of 150 households for Muntinlupa and 30 households for Parañaque were randomly selected through the use of rolling identical pieces of paper with the name of each community in it and then drawing the names after the pieces of paper had been thoroughly mixed. The sampling interval used in this study was the number 5 as determined by drawing a random number between 1 and 10. Households in each community were systematically sampled using the sampling interval.

A survey instrument, utilizing structured and openended questions was developed and pre-tested. The use of the structured and combined open-ended questions helps the investigators explore the demo graphic profile of the respondents, the perceptions and pertinent issues and new insights from the local community pertaining to the Laguna Lake. The self-administered questionnaire is used to preserve anonymity and ease in convincing the local community to answer the questions. The respondents' answers cannot be validated and the limited questions in the survey instrument are the identified limitations. The pre-tested questionnaire was handed at random from one household to every 5 th household thereafter.

The factors (age, gender, location of community, income, attitude towards the lake and the willingness to be involved in environmental efforts) were identified as the independent factors and the perception towards Laguna Lake was identified as the dependent factor. The correlation analysis was used to determine the factors significantly correlated with the perceptions of the local community towards the Laguna Lake. The Spearman's correlation analysis was used for the nonparametric data and the Pearson correlation analysis for the parametric data. Results yielding a p-value of 0.10 were significant. All statistical analysis was performed using the Statistical Package for Social Sciences (SPSS) software.

\section{RESULTS AND DISCUSSION}

A total of $173(96.1 \%)$ self-administered questionnaires handed to the householders of the two communities selected in Muntinlupa and Parañaque were returned. About 28 (93.3\%) householders from Parañaque and $145 \quad(96.7 \%)$ householders from Muntinlupa returned the self-administered questionnaires. Most of the householders surveyed are males $(59 \%)$ than females $(41 \%)$. The age of the respondents from the two communities ranged from 15-80 years. The mean $(+\mathrm{SD})$ age of respondents was $35 \pm 16$ years. A number of the respondents $(30.1 \%)$ have annual incomes ranging from a minimum of $\mathrm{PhP} 100, \quad 000$ to a maximum of PhP500, 000 $(\mathrm{PhP} 1=47$; minimum of $\$ 2,127.66$ to a maximum of $\$ 10,638.30$ ). About $28.9 \%$ of respondents had annual incomes more than PhP500, 000 (more than $\$ 10,638.30)$. There are more married $(49.7 \%)$ than single $(45.1 \%)$ respondents in the study.

The survey indicated that a majority of the local community $(68.2 \%)$ perceived that the water of Laguna Lake is polluted, while $16.8 \%$ perceived it to have historic and aesthetic value, $6.9 \%$ perceived it to be a good source of livelihood and offers an accessible route to navigating different places and $5.2 \%$ gave no perceptions towards the Lake. The majority of the local community $(86.2 \%)$ surveyed stated that they viewed the Laguna Lake to be an important resource and felt positively on the numerous benefits it provides to the general public. These respondents identified that there are multiple uses provided by the lake. The common uses viewed by the respondents towards the lake include a source of livelihood and water supply $(31.8 \%)$, for different consumption uses $(21.4 \%)$, for livelihood, water supply and navigational uses (19.1\%) and source of livelihood and food (13.9\%). Among those respondents who had negative views towards the Laguna Lake $(13.8 \%)$ had indicated that the Laguna Lake is polluted and hence it's worthless.

All the respondents of the study recognized that the Laguna Lake is deteriorating because of pollution. Majority (42.2\%) acknowledged that the source of pollution affecting the lake is because of the solid and liquid wastes discharged by industries and communities situated along the periphery of the lake. About 30.1\% of respondents specified that the problem of pollution is significantly contributed by the discharge of wastes by communities surrounding the lake. About $25.4 \%$ identified that wastes discharged by industries and motorboats navigating and used by fishermen on the lake contribute the source of pollution. All the respondents have indicated that their perception 
towards the lake is shaped by influences. A number $(36.4 \%)$ of respondents had indicated that the physical characteristics or the condition of the lake that includes the water discoloration, death of fishes and the presence of sewage influence their perception towards the lake. About $28.3 \%$ indicated that the existence of trash and or solid wastes influences their perception towards the lake. Only a small proportion of respondents (4.6\%) indicated that news reports influences their perception towards the lake.

Respondents were asked regarding their views towards the lake if it was polluted. A number of respondents $(31.8 \%)$ viewed that the pollution affecting the lake contributes to the deterioration of the environment. About $23.1 \%$ of respondents perceived that if the lake were polluted, a number of individuals would suffer, as it can no longer provide the general public's basic necessities like food and water sources. About $18.5 \%$ of respondents sights that the pollution of the lake will result to a decline on the fishes and aquatic organisms in the lake. A number $(9.2 \%)$ of respondents envisioned that there would be people losing their jobs and having problems that will affect their livelihood. Majority of the respondents $(94.2 \%)$ specified that the continuous deterioration of the lake creates an immense problem and there is a need to protect and manage the lake. Respondents (37\%) indicated that there is a need for government agencies to be actively involved particularly in monitoring and organizing clean ups for Laguna Lake and in implementing the laws and ordinances and the imposition of a budget to provide programs for the protection of the lake $(32.9 \%)$. Respondents $(15.6 \%)$ likewise indicated that instituting and implementing environmental management measures could help in sustainably managing the lake. Respondents $(26.6 \%)$ also stated that they themselves could help contribute in the protection of the lake by donating money and paying their appropriate taxes to help conserve, manage and protect the lake for the succeeding years. Respondents $(20.2 \%)$ also indicated that they themselves could help in actively participating in programs like lending their time for lake clean up activities.

The factors influencing the frame of reference of the perceptions of the respondents towards the Laguna Lake is significantly correlated by their attitudes towards the lake, respondents' income and their willingness to be involved in environmental efforts $(\mathrm{p}<0.10)$ (Table 1). This study does not negate the possibility that other factors may significantly influence the perceptions of respondents towards the lake.

This study was cross-sectional and its scope was limited to householders living near and away from the
Table 1: Factors related to the public perceptions of the local communities to wards the Laguna Lake

\begin{tabular}{lrl}
\hline Factors & $\mathrm{R}$ & $\mathrm{P}$ \\
\hline Age & 0.119 & $0.119^{\mathrm{NS}}$ \\
Gender & -0.053 & $0.490^{\mathrm{NS}}$ \\
Location of community & 0.065 & $0.396^{\mathrm{NS}}$ \\
Income & 0.148 & $0.066^{*}$ \\
Attitude towards the lake & -0.163 & $0.032^{*}$ \\
Willingness to be involved in & -0.143 & $0.060^{*}$ \\
environmental efforts & & \\
\hline
\end{tabular}

p-values: $*$ : $<<0.10 ;$ NS: Not significant

Laguna Lake. The findings of the study showed that majority of the householders surveyed recognize the importance of the Laguna Lake because of the multiple uses it provides however, it is constantly threatened by pollution. Result of the study showed that the householders perceived that the lake is continuously deteriorating due to pollution brought about by both solid and liquid wastes discharged by industries and communities that are situated along the periphery of the Laguna Lake. Similar findings support the results of this study as Montenegro ${ }^{[8]}$ indicates that the lake's pollution is greatly contributed by both domestic wastes from communities and wastes discharged by industries. Householders recognize that the waters of Laguna Lake are polluted due to the physical characteristics or conditions that the lake emanates. Results of the study showed that generally the perceptions of the respondents are shaped by their experience with the lake.

Results likewise showed that the perception of respondents towards the lake is influenced by various factors as supported by Zaltman and Wallendorf ${ }^{[9]}$. This study also presents that the factors like attitudes, income and the willingness to be involved in environmental efforts were significantly correlated to the respondents' perception towards the Laguna Lake. This study does not cancel out the possibility that other factors may significantly shape ones' perception. Their willingness to be involved in environmental efforts has shown varying influences in the perception of the lake. In a similar study by Pollnac ${ }^{[10]}$, it discusses how people's value of a resource can have significant implications on one's perceptions and on how they want resources managed. The positive attitudes towards the lake indicated by the respondents surveyed also helped shaped the local community's perception. Bohner and Wanke ${ }^{[11]}$ indicated that attitudes encompass the affective, behavioral and cognitive responses that may influence the frame of references of what people's perceptions are and the concerns people give. Income influences the perception of the householders surveyed. People with higher incomes showed better understanding of the activities 
surrounding the lake. A similar study ${ }^{[12]}$ presented that people's perception regarding the environment are highly differentiated among the community members based on their socioeconomic status. Cinner and Pollnac ${ }^{[12]}$ suggested that wealthier respondents are more likely to be understandable and amenable to the holistic approach of resource management.

\section{CONCLUSION}

This study presents that Laguna Lake is an important lake providing numerous uses for the general public. Common benefits recognized by the respondents include a source of livelihood, water supply, route of transportation and food source. The multiple uses of Laguna Lake recognize an immense threat that continuously deteriorates the condition of the lake due to pollution. The study indicated that majority of the respondents presented that the cause of pollution affecting the lake is brought about by solid and liquid wastes discharged from communities and industries situated along the periphery of the lake. A number of respondents recognized that their physical experience with the lake influence their perceptions towards the lake. The study also presented that there is a need to protect and manage the lake for the benefit of the succeeding generations. The study recognizes that the government and the community need to be involved particularly in safeguarding the Laguna Lake because numerous individuals and organisms depend on it. The study indicates that each one in society can partake or contribute in improving and mitigating the present conditions of Laguna Lake. The study also acknowledges that people's perceptions towards the lake are shaped by significant influences like attitudes, income and the willingness to be involved in environmental efforts towards the lake.

The conflict arising from the multiple uses of the environment is an immense problem that needs to be resolved because of its impacts towards the environment and on people's lives. Considerable approaches are introduced to mitigate the impacts arising from these conflicts. In the Philippines, the national and local governments spend to implement measures to protect and manage the environment, yet these measures remain unsuccessful in remedying the problem raised by these conflicts and in the attainment of sustainability.

There is a need to look into interventions that integrates the perspectives of the local stakeholders particularly in resolving issues arising from the conflict use of the environment. These measures must recognize and build on what the local people find important. The value of creating a shared understanding of what is important and what they value from their environment creates an important foundation for future researches, programs and policies that scientists, policy makers and even resource managers to consider. Surveys that integrate resource inventories with information on how people view and value these resources and the environment can help improve the conservation efforts being implemented in the Philippines.

There is likewise a need to develop longitudinal studies that will anticipate what policies might achieve sustainability particularly in managing the Philippine environment and the world. There is also a need to consider what possible factors that may significantly shape the general public's relations on the environment, perception and on how these may all affect the status and the sustainability of resource and the environment and that of the general public's well being.

\section{ACKNOWLEDGEMENT}

The researchers wish to extend their grateful appreciation to the local communities who participated in the study and all others who have supported this study in one way or another.

\section{REFERENCES}

1. Smith, S.E. and M. Al-Rawahy, 1990. The blue nile: Potential for conflict and alternatives for meeting future demands. Water Int., 15: 217-222.

2. Ashton, P.J., 2003. Avoiding conflicts over Africa's water resources. Ambio., 31: 236-242.

3. Studsrod, J.E. and P. Wegge, 1995. Park people relationships: The case of damages caused by park animals around the Royal Bardia National Park. Nepal, Environ. Conserv., 22: 133-142.

4. Nepal, S.K. and K.E. Weber, 1995. Managing resources and resolving conflicts: National parks and local people. Int. J. Sustain. Develop. World Ecol., 2: 11-25.

5. Hough, J.L., 1997. Obstacle to effective management of conflicts between national parks and surrounding human communities in developing countries. Environ. Conserv., 15: 129-135.

6. Woelcke, J., 2002. Soil mining in Eastern Uganda. Newsletter of the International Human Dimensions Programme on Global Environmental Change, April, 1.

7. Wells, W., J. Barnett and S. Moriarty, 1995. Advertising: Principles and Practice. 3rd Edn. Prentice-Hall, Inc., New Jersey, USA. 
8. Montenegro, L.O., 2006. Inspections, enforcement and water pollution discharges in Laguna Lake, Philippines. http://www.phileconsociety.org/ portals/0/downloads/44th\%20meeting/ps4_monten egro.pdf.

9. Zalthman, G. and M. Wallendorf, 1979. Consumer Behavior: Basic Findings and Management Implications. John Wiley and Sons, New York, USA.

10. Pollnac, R.B., 2000. The perceptions of the coastal environment in Indonesia. http://www.crc.uri. edu/download/CM_pollnac.pdf.
11. Bohner, G. M. and Wanke, 2002. Attitudes and Attitude Change. Psychology Press, Ltd., United Kingdom, pp: 3-242.

12. Cinner, J.E. and R.B. Pollnac, 2004. Poverty, perceptions and planning: why socioeconomics matter in the management of Mexican reefs. http://www.Cinnerpollnac.pdf. 